\title{
A Comparative Assessment of the Antibacterial Efficacy of Licorice Mouth-Rinse with Chlorhexidine on Salivary Streptococcus mutans
}

\author{
Jayashree Pathi ${ }^{1}$, Kumudini Panigrahi ${ }^{2}$, Ipsa Mohapatra ${ }^{3}$, Ratikanta Tripathy ${ }^{4}$ \\ ${ }^{1}$ Department of Public Health Dentistry, Kalinga Institute of Dental Sciences, KIIT University, \\ Bhubaneswar, Odisha, India. ${ }^{2}$ Department of Microbiology, Kalinga Institute of Medical Sciences, \\ KIIT University, Bhubaneswar, Odisha, India. ${ }^{3}$ Department of Community Medicine, Kalinga \\ Institute of Medical Sciences, KIIT University, Bhubaneswar, Odisha, India. ${ }^{4}$ Department of \\ Pharmacology, Kalinga Institute of Medical Sciences, KIIT University, Bhubaneswar, Odisha, India.
}

\section{ABSTRACT}

\section{BACKGROUND}

Dental and periodontal diseases are common problems worldwide. Strong association exists between Streptococcus mutans and dental caries. Mouthwashes like chlorohexidine and extracts of medicinal plants like liquorice have antimicrobial properties. The objective of the study was to compare the antimicrobial efficacy of licorice mouth-rinse with chlorhexidine on salivary Streptococcus mutans.

\section{METHODS}

A randomised control trial was undertaken in the department of Public Health Dentistry, in a tertiary care hospital of Bhubaneswar, Odisha. Children of both sexes, aged 7 to 14 years, with high risk of caries and providing willingness were included. The products used were Aqueous and Ethanolic licorice root extract - 15 gm and 375 $\mathrm{mg} / 10 \mathrm{ml}$ respectively, Chlorhexidine $0.12 \%$. MIC of the products against Streptococcus mutans was determined. The children were divided into three groups, fifteen in each. Each participant rinsed with $10 \mathrm{ml}$ of the randomly allocated prepared suspension for $1 \mathrm{~min}$. Five saliva samples were collected from each, one pre-rinse and four post-rinse 2 mins, 30 mins, 1 hour and 2 hours after the intervention. Streptococcus mutans colony count and salivary $\mathrm{pH}$ was used to study the efficacy of the mouthwashes.

\section{RESULTS}

The study revealed that ethanolic extract of licorice had better antimicrobial efficacy. The efficacy of antimicrobial action of licorice extract at 30 minutes of rinsing and rise in salivary $\mathrm{pH}$ by use of both the preparations of licorice was significant as compared to the chlorhexidine group.

\section{CONCLUSIONS}

The antimicrobial and cariostatic efficacy of licorice extracts which was evident in the present study suggests and recommends that licorice can be used as a preventive regimen in clinical practice for diseases of mouth cavity especially dental caries.

\section{KEY WORDS}

Dental Caries, Streptococcus mutans, Licorice, Chlorhexidine, Mouth Wash
Corresponding Author: Dr. Kumudini Panigrahi, Department of Microbiology, KIMS, KIIT University, Bhubaneswar, Odisha, India. E-mail: kumudini.disha@gmail.com

DOI: $10.14260 / \mathrm{jemds} / 2021 / 223$

How to Cite This Article: Pathi J, Panigrahi K, Mohapatra I, et al. A comparative assessment of the antibacterial efficacy of Licorice mouthrinse with Chlorhexidine on salivary Streptococcus mutans. J Evolution Med Dent Sci 2021;10(15):1042-1047, DOI: 10.14260/jemds/2021/223

Submission 17-11-2020,

Peer Review 13-02-2021,

Acceptance 19-02-2021,

Published 12-04-2021.

Copyright (C) 2021 Jayashree Pathi et al. This is an open access article distributed under Creative Commons Attribution License [Attribution 4.0 International (CC $B Y 4.0)]$ 


\section{BACKGROUND}

Oral diseases are a major health concern. Dental caries is a common and chronic childhood disease. ${ }^{1,2}$ The role of Streptococcus mutans (S. mutans) is well established in dental biofilm and caries formation, so preventive strategy has $\mathrm{S}$. mutans as its target.3,4,5 Mouthwashes help to reduce the microorganism load in the oral cavity. ${ }^{6}$ Chlorhexidine mouthwash is accepted as Gold Standard, but it has many adverse effects. ${ }^{7,8}$ Medicinal plants such as Glycyrrhiza glabra Linn (liquorice) is less costly and relatively safe. ${ }^{8}$ The Food and Drug Administration (FDA) lists licorice as GRAS (Generally Regarded as Safe) and has antimicrobial activities.9,10 But evidence regarding the antimicrobial efficacy is lacking.

We wanted to compare the antimicrobial efficacy of licorice mouth-rinse with chlorhexidine on salivary Streptococcus mutans.

\section{METHODS}

This was a randomised control trial, done with three comparison groups. The present study was carried out in Department of Public Health Dentistry, in collaboration with Department of Microbiology, of a medical university over a period of 3 months [from Oct - 2016 to Dec - 2016].

\section{Study Population}

Children of both sexes, of age between 7 to 14 years, voluntarily willing to participate in the study, having a highrisk caries criteria as established by the modified version of Axelsson Criteria for High Risk Caries, ${ }^{11}$ were included in the study. Subjects with history of taking antibiotics 3 months prior to or during the course of study, presence of crowns or restorations, extensive bridges or prosthetic constructions and orthodontic appliances, known intolerance or allergy to mouthwashes, age below 7 years were excluded from the study. The children were randomly allocated to one of the three groups, fifteen in each group. Group-1 [test] was the Ethanolic licorice root extract (ELR), Group-2 [positive control] was the chlorhexidine group (CLX) and Group-3 [test] was the aqueous licorice root extract (ALR).

\section{Sample Size}

Total sample size was calculated to be 45 , taking alpha - 0.05 (5\%), beta $-0.20(20 \%)$, power -0.80 (80 \%), effect size -0.25 (25\%, medium effect size). Total sample size -45 , each group size -15 , calculated using G Power 3.0.10 software.

\section{Sampling Technique}

Convenience sampling, for selection of study participants (subjects were selected from an orphanage in the study. The dietary pattern and the socioeconomic strata were thus, standardised); with blinded allocation of study subjects into the three study groups. The participant and investigator were both unaware which group got which mouthwash.

\section{Methodology}

The study was divided into two parts: In-vitro and in-vivo phase. Procurement of licorice plant: Root powder of licorice was collected from a registered ayurvedic centre in the city.

The aqueous and ethanolic extract of licorice mouthwash was prepared in Department of Pharmacology. Licorice root powder sample was soaked in distilled water [ratio 15 grams in $100 \mathrm{ml}$ ] and ethyl alcohol [ 15 grams in $100 \mathrm{ml}$ of $5 \%$ ethyl alcohol], respectively, for $24 \mathrm{~h}$ with intermittent shaking. The active ingredients that leached out in the solvent were subsequently filtered. The filtrate for each extract was concentrated using a rotavapor and freeze dried using lyophilisation, following which the residues were finely ground, weighed, and stored at $4^{\circ} \mathrm{C}$ for further experiments.

In-vitro phase: Evaluation of minimum inhibitory concentration (MIC): The aqueous and ethanolic extract of licorice root was prepared and antibacterial activity of these extracts was assessed by evaluating the MIC and minimum bactericidal concentration (MBC) against S. mutans.

A stock solution $(30 \%$ concentration of the extract in normal saline) was taken and 10 subsequent doubling dilutions of each extract was made to obtain concentrations of $15 \%, 7.5 \%, 3.75 \%, 1.88 \%, 0.94 \%, 0.47 \%, 0.23 \%, 0.12 \%$, $0.06 \%$, and $0.03 \%$, respectively. To each of the 10 test tubes, brain heart infusion (BHI) broth and an equal volume of $\mathrm{S}$. mutans adjusted to 0.5 McFarland was added. After incubation, MIC was detected by visual inspection. ${ }^{12}$ The lowest concentration of the test agent showing no visible turbidity is considered to be the MIC. Small aliquots were taken from all the tubes in which no visible bacterial growth would had been observed, and seeded into Mueller-Hinton Agar (MHA) and were incubated overnight at $37^{\circ} \mathrm{C}$. The concentration at which no colonies of S. mutans appeared were inferred to be the MBC.

In-vivo phase: Forty five subjects having, $\geq 10^{5} \mathrm{CFU}$ of $\mathrm{S}$. mutans per $\mathrm{ml}$ of saliva were selected and equally divided into 3 groups

The products used in the present study were: aqueous licorice root extract - $15 \mathrm{~g} / 10 \mathrm{ml}$, ethanolic licorice root extract - $375 \mathrm{mg} / 10 \mathrm{ml}$ and commercially available Chlorhexidine mouthwash-Conc. of $0.12 \%$. Each suspension was dispensed in $10 \mathrm{ml}$ amount at one time. All of the three mouthwashes were dispensed in similar looking opaque bottles. All the children participating in the present study were instructed not to brush their teeth on the day of sampling. Unstimulated saliva samples were collected $2 \mathrm{~h}$ after the meal. The children were randomly divided into the groups and the pre-weighed dose of the allocated drug material was delivered by the examiner for mouth rinsing

Each child was required to rinse with $10 \mathrm{ml}$ of the randomly allocated prepared suspension in the respective group for a period of $1 \mathrm{~min}$. Accumulated saliva in the mouth is collected into sterile, labelled saliva collecting cups. Thus, for each patient, five saliva samples were collected, i.e. one prerinse sample and four post-rinse samples collected 2 minutes, 30 minutes, 1 hour and 2 hours after the mouth rinsing. The $\mathrm{pH}$ of the unstimulated whole saliva collected at each interval was analysed using a chair side kit (GC Saliva Check). The pH paper was dipped in the sample for at least $10 \mathrm{sec}$ and the colour change was compared with the chart provided by the manufacturer. 
The salivary samples for each individual were collected in collecting cups in the Department of Microbiology, where inoculation was done on Sheep BA plate and incubated in candle jar at 37 degree $C$ for 24 hours. Confirmation of $S$. mutans was performed from colony morphology and Gram staining finding of the smear done from the colony on SBA and biochemical tests. Microbial counts were expressed as colony forming units (CFUs) per millilitre of saliva.

The values of $\mathrm{pH}$ and counts of CFUs of S. mutans were recorded and intergroup comparisons were made at baseline (pre-rinsing) and after the mouth rinsing procedure.

Study tool for data collection: Proforma was used for collecting data regarding the participant's name, age, gender, oral hygiene practices and dietary habits.

\section{Statistical Analysis}

Statistical analysis was done by SPSS version 23. Data collected was expressed as percentage, frequencies and means. Association was found by using paired t-test and one way ANOVA. Pair wise comparisons by Tukey's multiple post hoc procedures. Chi-square and one way analysis of variance were used to compare the baseline information among the subjects of 3 study groups. Paired t-test was used to evaluate the statistical significance of the mean difference in change of $\mathrm{pH}$ between respective time intervals from baseline after using the mouthwash. Statistically significant differences between groups were compared using Tukey's multiple post hoc procedures.

Ethical implication: Ethical clearance and approval were obtained from the Institutional Ethics Committee. Participation was voluntary and subjects gave verbal assent and written informed consent was taken from their guardian / caregiver, before administering mouth rinse. The caregivers had been told that the information obtained from them will be kept completely confidential.

\section{RESULTS}

In this study, designed to compare the antimicrobial efficacy of licorice mouth rinse with chlorhexidine on salivary Streptococcus mutans, a total of 45 children were recruited, among which males were in overwhelmingly majority, representing $68.89 \% 31$ of the total population. Mean age for the ethanolic, chlorhexidine and aqueous groups were 9.27, 9.47 and 9.40 respectively. [Table 1]

It was seen from the data regarding oral hygiene collected in the proforma that majority of study subjects in group 1 and 3 brushed their teeth twice $(53.33 \%$ and $60 \%$ respectively) and a higher percentage of study subjects in group 2 (53.33\%) brushed their teeth once a day; but the overall comparison between groups using chi-square test showed that there was no significant difference between the groups for frequency of tooth brushing (between the three groups, Chi-square = 2.0094 and $P=0.7341)$. (Chart 1$)$

\begin{tabular}{|ccccccccc|}
\hline & Group 1 & \% & Group 2 & \% & Group 3 & \% & Total & \% \\
Male & 10 & 66.67 & 10 & 66.67 & 11 & 73.33 & 31 & 68.89 \\
Female & 5 & 33.33 & 5 & 33.33 & 4 & 26.67 & 14 & 31.11 \\
Total & 15 & 100.00 & 15 & 100.00 & 15 & 100.00 & 45 & 100.00 \\
Mean age & 9.27 & 9.47 & 9.20 & 9.31 \\
SD age & 1.33 & 1.64 & 1.70 & 1.53 \\
\hline \multicolumn{7}{c|}{ Table 1. Distribution of Male and Females with } \\
Mean and SD Age in the Three Study Groups (1, 2, 3)
\end{tabular}

\begin{tabular}{|c|c|c|c|c|c|c|c|c|c|c|}
\hline \multirow{2}{*}{ Groups } & \multicolumn{2}{|c|}{ Baseline } & \multicolumn{2}{|c|}{2 Minutes } & \multicolumn{2}{|c|}{30 Minutes } & \multicolumn{2}{|c|}{1 Hour } & \multicolumn{2}{|c|}{2 Hours } \\
\hline & Mean & SD & Mean & SD & Mean & SD & Mean & SD & Mean & SD \\
\hline Group 1 & 6.67 & 0.41 & 9.13 & 0.93 & 8.83 & 0.90 & 8.30 & 0.88 & 8.33 & 0.88 \\
\hline Group 2 & 6.53 & 0.55 & 7.13 & 0.61 & 7.63 & 0.85 & 7.83 & 0.82 & 7.33 & 0.70 \\
\hline Group 3 & 8.10 & 0.87 & 8.93 & 1.19 & 9.30 & 1.13 & 9.57 & 1.28 & 8.30 & 0.98 \\
\hline F-value & \multicolumn{2}{|c|}{27.6874} & \multicolumn{2}{|c|}{20.4385} & \multicolumn{2}{|c|}{11.8007} & \multicolumn{2}{|c|}{11.7405} & \multicolumn{2}{|c|}{6.5418} \\
\hline P-value & \multicolumn{2}{|c|}{$0.0001 *$} & \multicolumn{2}{|c|}{$0.0001^{*}$} & \multicolumn{2}{|c|}{$0.0001^{*}$} & \multicolumn{2}{|c|}{$0.0001^{*}$} & \multicolumn{2}{|c|}{$0.0034^{*}$} \\
\hline \multicolumn{11}{|c|}{ Pair Wise Comparisons by Tukey's Multiple Post Hoc Procedures } \\
\hline $\begin{array}{c}\text { Group } 1 \\
\text { vs. Group } \\
2\end{array}$ & \multicolumn{2}{|c|}{$P=0.8362$} & \multicolumn{2}{|c|}{$P=0.0001^{*}$} & \multicolumn{2}{|c|}{$P=0.0044^{*}$} & \multicolumn{2}{|c|}{$P=0.4251$} & \multicolumn{2}{|c|}{$P=0.0077^{*}$} \\
\hline $\begin{array}{c}\text { Group } 1 \\
\text { vs. Group } \\
3\end{array}$ & \multicolumn{2}{|c|}{$\mathrm{P}=0.0001^{*}$} & \multicolumn{2}{|c|}{$\mathrm{P}=0.8314$} & \multicolumn{2}{|c|}{$P=0.3931$} & \multicolumn{2}{|c|}{$\mathrm{P}=0.0040^{*}$} & \multicolumn{2}{|c|}{$\mathrm{P}=0.9939$} \\
\hline $\begin{array}{c}\text { Group } 2 \\
\text { vs. Group } \\
3\end{array}$ & \multicolumn{2}{|c|}{$P=0.0001 *$} & \multicolumn{2}{|c|}{$P=0.0001^{*}$} & \multicolumn{2}{|c|}{$\mathrm{P}=0.0002^{*}$} & \multicolumn{2}{|c|}{$P=0.0002^{*}$} & \multicolumn{2}{|c|}{$P=0.0101^{*}$} \\
\hline \multicolumn{11}{|c|}{$\begin{array}{l}\text { Table 2. Comparison of Mean Salivary pH of the Three Study Groups } \\
\text { (1, 2, 3) Collected at } 2 \text { Minutes, } 30 \text { Minutes, } 1 \text { Hour and } 2 \text { Hours } \\
\text { Intervals with Respect to Baseline pH by One Way ANOVA }\end{array}$} \\
\hline
\end{tabular}

\begin{tabular}{|c|c|c|c|c|c|c|c|c|}
\hline \multirow{3}{*}{ Groups } & \multicolumn{8}{|c|}{ Changes from Baseline to } \\
\hline & \multicolumn{2}{|c|}{2 Minutes } & \multicolumn{2}{|c|}{30 Minutes } & \multicolumn{2}{|c|}{1 Hour } & \multicolumn{2}{|c|}{2 Hours } \\
\hline & Mean & SD & Mean & SD & Mean & SD & Mean & SD \\
\hline Group 1 & 2.47 & 0.74 & 2.17 & 0.75 & 1.63 & 0.77 & 1.67 & 0.75 \\
\hline Group 2 & 0.60 & 0.39 & 1.10 & 0.66 & 1.30 & 0.62 & 0.80 & 0.59 \\
\hline Group 3 & 0.83 & 0.77 & 1.20 & 0.86 & 1.47 & 1.06 & 0.20 & 0.37 \\
\hline $\begin{array}{c}\% \text { of change } \\
\text { in } \\
\text { Group } 1\end{array}$ & \multicolumn{2}{|c|}{$\begin{array}{c}37.00 \% \#, P= \\
0.0001^{*}\end{array}$} & \multicolumn{2}{|c|}{$\begin{array}{c}32.50 \% \#, P= \\
0.0001^{*}\end{array}$} & \multicolumn{2}{|c|}{$\begin{array}{c}24.50 \% \#, P= \\
0.0001^{*}\end{array}$} & \multicolumn{2}{|c|}{$\begin{array}{c}25.00 \% \#, P= \\
0.0001^{*}\end{array}$} \\
\hline $\begin{array}{c}\% \text { of change } \\
\text { in } \\
\text { Group } 2\end{array}$ & \multicolumn{2}{|c|}{$\begin{array}{c}9.18 \% \#, P= \\
0.0001^{*}\end{array}$} & \multicolumn{2}{|c|}{$\begin{array}{c}16.84 \% \#, P= \\
0.0001^{*}\end{array}$} & \multicolumn{2}{|c|}{$\begin{array}{c}19.90 \% \#, P= \\
0.0001^{*}\end{array}$} & \multicolumn{2}{|c|}{$\begin{array}{c}12.24 \% \#, P= \\
0.0001^{*}\end{array}$} \\
\hline $\begin{array}{c}\% \text { of change } \\
\text { in } \\
\text { Group } 3\end{array}$ & \multicolumn{2}{|c|}{$\begin{array}{c}10.29 \% \#, P= \\
0.0001^{*}\end{array}$} & \multicolumn{2}{|c|}{$\begin{array}{c}14.81 \% \#, \mathrm{P}= \\
0.0001^{*}\end{array}$} & \multicolumn{2}{|c|}{$\begin{array}{c}18.11 \% \#, P= \\
0.0001^{*}\end{array}$} & \multicolumn{2}{|c|}{$\begin{array}{c}2.47 \% \#, P= \\
0.0541\end{array}$} \\
\hline F-value & \multicolumn{2}{|c|}{35.8734} & \multicolumn{2}{|c|}{8.9849} & \multicolumn{2}{|c|}{0.5959} & \multicolumn{2}{|c|}{23.4077} \\
\hline P-value & \multicolumn{2}{|c|}{$0.0001^{*}$} & \multicolumn{2}{|c|}{$0.0006^{*}$} & \multicolumn{2}{|c|}{0.5557} & \multicolumn{2}{|c|}{$0.0001 *$} \\
\hline \multicolumn{9}{|c|}{ Pair Wise Comparisons by Tukey's Multiple Post Hoc Procedures } \\
\hline $\begin{array}{l}\text { Group } 1 \text { vs. } \\
\text { Group } 2\end{array}$ & \multicolumn{2}{|c|}{$P=0.0001^{*}$} & \multicolumn{2}{|c|}{$P=0.0013^{*}$} & \multicolumn{2}{|c|}{$P=0.5245$} & \multicolumn{2}{|c|}{$P=0.0008^{*}$} \\
\hline $\begin{array}{l}\text { Group } 1 \text { vs. } \\
\text { Group } 3\end{array}$ & \multicolumn{2}{|c|}{$\mathrm{P}=0.0001^{*}$} & \multicolumn{2}{|c|}{$\mathrm{P}=0.0034^{*}$} & \multicolumn{2}{|c|}{$P=0.8492$} & \multicolumn{2}{|c|}{$P=0.0001^{*}$} \\
\hline $\begin{array}{l}\text { Group } 2 \text { vs. } \\
\text { Group } 3\end{array}$ & \multicolumn{2}{|c|}{$P=0.5987$} & \multicolumn{2}{|c|}{$P=0.9313$} & & 0.8492 & & $.0216^{*}$ \\
\hline
\end{tabular}

Table 3. Comparison of Change in Salivary pH among the Three Study Groups $(1,2,3)$ Collected at 2 Minutes, 30 Minutes, 1 Hour and 2 Hours Post Rinse Interval with Respect to the Baseline by One Way ANOVA $* \mathrm{P}<0.05$, \# applied Paired t test

The mean pH values of salivary samples in the three study groups at the different time intervals was analysed and observed that there was a rise in salivary $\mathrm{pH}$ among all the three groups with respect to the baseline. (Table 2)

When change in $\mathrm{pH}$ is compared among the three groups in different intervals with respect to base line $\mathrm{pH}$, alcoholic extract group showed the highest rise in $\mathrm{pH}$ up to the $2 \mathrm{hr}$ salivary sample. The group wise comparisons showed highly statistical significance for all the time intervals. (Table 3)

The three study groups were compared by one way ANOVA about CFUs grown on blood agar from salivary samples collected in post rinse 2 minutes, 30 minutes, 1 hour and 2 hours intervals with respect to baseline. 


\begin{tabular}{|c|c|c|c|c|c|c|c|c|c|c|}
\hline \multirow{2}{*}{ Groups } & \multirow{2}{*}{\multicolumn{2}{|c|}{$\begin{array}{l}\text { Baseline } \\
\text { Mean SD }\end{array}$}} & \multicolumn{2}{|c|}{2 Minutes } & \multicolumn{2}{|c|}{30 Minutes } & \multicolumn{2}{|c|}{1 Hour } & \multicolumn{2}{|c|}{2 Hours } \\
\hline & & & Mean & SD & Mean & SD & Mean & SD & Mean & SD \\
\hline Group 1 & 5.84 & 0.59 & 5.61 & 0.68 & 0.74 & 1.19 & 1.19 & 1.42 & 5.53 & 0.54 \\
\hline Group 2 & 5.55 & 0.64 & 0.03 & 0.03 & 1.72 & 1.33 & 4.25 & 0.73 & 5.33 & 0.76 \\
\hline Group 3 & 5.99 & 0.56 & 5.95 & 0.60 & 3.38 & 1.15 & 3.22 & 1.23 & 5.49 & 0.72 \\
\hline F-value & \multicolumn{2}{|c|}{2.1010} & \multicolumn{2}{|c|}{603.4460} & \multicolumn{2}{|c|}{17.8046} & \multicolumn{2}{|c|}{26.8664} & \multicolumn{2}{|c|}{0.3601} \\
\hline P-value & \multicolumn{2}{|c|}{0.1350} & \multicolumn{2}{|c|}{$0.0001^{*}$} & \multicolumn{2}{|c|}{ 0.0001* } & \multicolumn{2}{|c|}{$0.0001^{*}$} & \multicolumn{2}{|c|}{0.6998} \\
\hline \multicolumn{11}{|c|}{ Pair Wise Comparisons by Tukey's Multiple Post Hoc Procedures } \\
\hline $\begin{array}{c}\text { Group } 1 \\
\text { vs. Group } \\
2\end{array}$ & \multicolumn{2}{|c|}{$P=0.3805$} & \multicolumn{2}{|c|}{$P=0.0001^{*}$} & \multicolumn{2}{|c|}{$P=0.0834$} & \multicolumn{2}{|c|}{$P=0.0001^{*}$} & \multicolumn{2}{|c|}{$P=0.7040$} \\
\hline $\begin{array}{c}\text { Group } 1 \\
\text { vs. Group } \\
3\end{array}$ & \multicolumn{2}{|c|}{$P=0.7816$} & \multicolumn{2}{|c|}{$P=0.1906$} & \multicolumn{2}{|c|}{$P=0.0001^{*}$} & \multicolumn{2}{|c|}{$\mathrm{P}=0.0002^{*}$} & \multicolumn{2}{|c|}{$P=0.9860$} \\
\hline $\begin{array}{c}\text { Group } 2 \\
\text { vs. Group } \\
3 \\
\end{array}$ & \multicolumn{2}{|c|}{$P=0.1217$} & \multicolumn{2}{|c|}{$P=0.0001^{*}$} & \multicolumn{2}{|c|}{$P=0.0018^{*}$} & \multicolumn{2}{|c|}{$P=0.0514$} & \multicolumn{2}{|c|}{$P=0.7982$} \\
\hline \multicolumn{11}{|c|}{$\begin{array}{c}\text { Table 4. Comparison CFUs on BA from Salivary Samples } \\
\text { of the Three Study Groups at Different Intervals with } \\
\text { Respect to Baseline by One Way ANOVA }\end{array}$} \\
\hline 0.05 & & & & & & & & & & \\
\hline
\end{tabular}

\begin{tabular}{|c|c|c|c|c|c|c|c|c|}
\hline \multirow{3}{*}{ Groups } & \multicolumn{8}{|c|}{ Changes from Baseline to } \\
\hline & \multicolumn{2}{|c|}{2 Minutes } & \multicolumn{2}{|c|}{30 Minutes } & \multicolumn{2}{|c|}{1 Hour } & \multicolumn{2}{|c|}{2 Hours } \\
\hline & Mean & SD & Mean & SD & Mean & SD & Mean & SD \\
\hline Group 1 & 0.23 & 0.25 & 5.10 & 1.40 & 4.65 & 1.38 & 0.31 & 0.52 \\
\hline Group 2 & 5.52 & 0.62 & 3.82 & 1.37 & 1.30 & 0.64 & 0.21 & 0.44 \\
\hline Group 3 & 0.03 & 0.13 & 2.61 & 1.07 & 2.77 & 1.10 & 0.49 & 0.78 \\
\hline $\begin{array}{l}\% \text { of change in } \\
\text { Group } 1\end{array}$ & \multicolumn{2}{|c|}{$\begin{array}{c}3.88 \% \#, \mathrm{P}= \\
0.0031^{*}\end{array}$} & \multicolumn{2}{|c|}{$\begin{array}{c}87.27 \% \#, P= \\
0.0001^{*}\end{array}$} & \multicolumn{2}{|c|}{$\begin{array}{c}79.65 \% \#, P= \\
0.0001^{*}\end{array}$} & \multicolumn{2}{|c|}{$\begin{array}{l}5.25 \mathrm{p}= \\
0.0386^{*}\end{array}$} \\
\hline $\begin{array}{l}\% \text { of change in } \\
\text { Group } 2\end{array}$ & \multicolumn{2}{|c|}{$\begin{array}{c}99.53 \% \#, P= \\
0.0001^{*}\end{array}$} & \multicolumn{2}{|c|}{$\begin{array}{c}68.91 \% \#, P= \\
0.0001^{*}\end{array}$} & \multicolumn{2}{|c|}{$\begin{array}{c}23.44 \% \#, P= \\
0.0001^{*}\end{array}$} & \multicolumn{2}{|c|}{$\begin{array}{c}3.85 \% \#, P= \\
0.0787\end{array}$} \\
\hline $\begin{array}{c}\% \text { of change in } \\
\text { Group } 3\end{array}$ & \multicolumn{2}{|c|}{$\begin{array}{c}0.56 \% \#, P= \\
0.3343\end{array}$} & \multicolumn{2}{|c|}{$\begin{array}{c}43.54 \% \#, P= \\
0.0001^{*}\end{array}$} & \multicolumn{2}{|c|}{$\begin{array}{c}46.21 \% \#, P= \\
0.0001^{*}\end{array}$} & \multicolumn{2}{|c|}{$\begin{array}{c}8.24 \% \#, P= \\
0.0282^{*}\end{array}$} \\
\hline F-value & \multicolumn{2}{|c|}{934.2108} & \multicolumn{2}{|c|}{14.0152} & \multicolumn{2}{|c|}{36.1659} & \multicolumn{2}{|c|}{0.8551} \\
\hline P-value & \multicolumn{2}{|c|}{0.0000} & \multicolumn{2}{|c|}{0.0000} & \multicolumn{2}{|c|}{0.0000} & \multicolumn{2}{|c|}{0.4325} \\
\hline \multicolumn{9}{|c|}{ Pair Wise Comparisons by Tukey's Multiple Post Hoc Procedures } \\
\hline $\begin{array}{l}\text { Group } 1 \text { vs. } \\
\text { Group } 2\end{array}$ & \multicolumn{2}{|c|}{$\mathrm{P}=0.0001$} & \multicolumn{2}{|c|}{$\mathrm{P}=0.0259$} & \multicolumn{2}{|c|}{$\mathrm{P}=0.0001$} & \multicolumn{2}{|c|}{$P=0.9042$} \\
\hline $\begin{array}{l}\text { Group } 1 \text { vs. } \\
\text { Group } 3\end{array}$ & \multicolumn{2}{|c|}{$P=0.3805$} & \multicolumn{2}{|c|}{$P=0.0001$} & \multicolumn{2}{|c|}{$P=0.0002$} & \multicolumn{2}{|c|}{$P=0.6707$} \\
\hline $\begin{array}{l}\text { Group } 2 \text { vs. } \\
\text { Group } 3 \\
\end{array}$ & \multicolumn{2}{|c|}{$P=0.0001$} & $P=0$ & .0350 & $P=0$ & .0018 & $P=0$ & 4119 \\
\hline $\begin{array}{l}\text { Table 5. Con } \\
\text { Respect to }\end{array}$ & $\begin{array}{l}\text { iparison } \\
\text { Changes }\end{array}$ & $\begin{array}{l}\text { amon } \\
\text { in CFL } \\
\text { iselint }\end{array}$ & $\begin{array}{l}g \text { the Tl } \\
\text { US on Blc } \\
\text { e by One }\end{array}$ & $\begin{array}{l}\text { ree stı } \\
\text { od Agc } \\
\text { Way A }\end{array}$ & $\begin{array}{l}\text { udy Gro } \\
\text { ar Cult } \\
\text { ANOVA }\end{array}$ & $\begin{array}{l}\text { oups (1 } \\
\text { ure [in }\end{array}$ & $\begin{array}{l}1,2,3) \mathrm{v} \\
\left.10^{5}\right] \mathrm{frc}\end{array}$ & \\
\hline$<0.05$, \# app & Paired & & & & & & & \\
\hline
\end{tabular}

The colony counts reduced from the baseline value in all the subsequent time intervals for the three groups. The number of colonies for alcoholic group was $1.19 \pm 1.42$ at 1 hour from baseline, was $0.03 \pm 0.03$ at 2 minutes from baseline for the chlorhexidine group and for the aqueous group it was $3.38 \pm 1.15$ at 30 minutes from baseline. (Table 4)

Comparison of CFUs on blood agar from post rinse salivary samples collected at 2 minutes, 30 minutes, 1 hour and 2 hours interval from Baseline among the three study groups was done by one way ANOVA. The mean reduction of colony counts for the aqueous group was 0.23 , for chlorhexidine was 5.52 and for alcoholic group was 0.03 colonies in $10^{5}$ units. (Table 5) The highest reduction of colonies for aqueous group was at 30 min. from baseline, for chlorhexidine group it was at 2 mins from baseline. Similarly for alcoholic group, the highest reduction was at 1 hour from baseline.

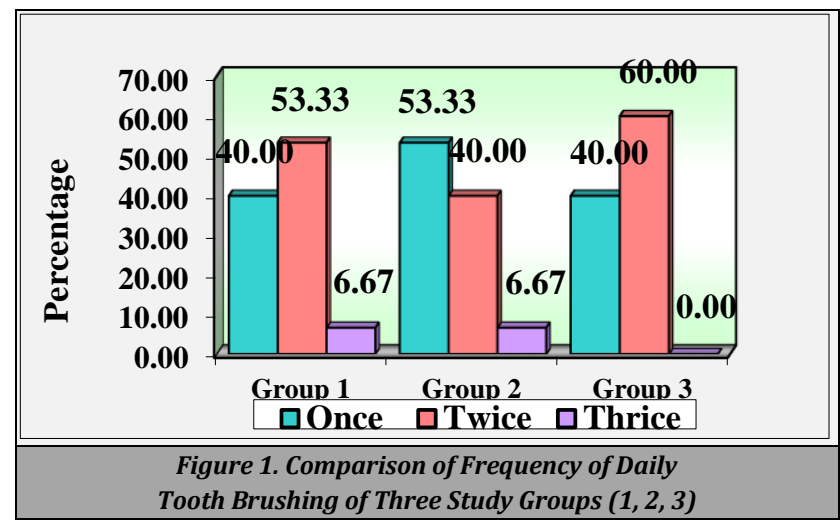

\section{DISCUSSION}

The present study was done to compare the antimicrobial efficacy of Licorice mouth rinse with chlorhexidine on salivary Streptococcus mutans carried out in department of public health dentistry in a tertiary care hospital.

In this study, a total of 45 children were recruited, among which males were in overwhelmingly majority, representing $68.89 \%$ (31) of the total population. Mean age for the ethanolic, chlorhexidine and aqueous groups were 9.27, 9.47 and 9.40 respectively. The efficacy of licorice extracts was evaluated in vitro as well as after a single topical application in the oral cavity, using chlorhexidine as a positive control.

Results of the in vitro experiment revealed that ethanolic extract of licorice had better antimicrobial activity than the aqueous extracts. These findings are in agreement with the observations of Ahmad et al., who concluded that alcohol is a better solvent than water..$^{13}$ This might be attributed to the polar nature of the solvent, i.e. ethanol, which resulted in leaching of more active ingredients during extraction. Variation of susceptibility of the pathogens to aqueous and ethanolic extracts indicates the involvement of more than one active principle of biological significance.

In the present study, chlorhexidine was used in a concentration of $0.12 \%$ in accordance with the MBC assessed for the study. Segreto et al. also concluded that $0.1 \%$ twice daily administration offers the same clinical benefits as a 0.2 $\%$ chlorhexidine solution. ${ }^{14}$

In this study, the pH levels of the saliva samples were seen to be significantly correlated with frequency of tooth brushing for the ethanolic extract. This might be due to the fact that tooth brushing increased the secretion of the parotid gland, probably via the activation of periodontal mechanoreceptors. ${ }^{15}$ Hoek et al. demonstrated that salivary flow increased $15 \%$ after tooth brushing. ${ }^{16}$ In another study, tooth brushing increased the production of saliva in patients affected by xerostomia. ${ }^{17}$

Licorice is also known to be an alkaline food and has a protective effect in gastro oesophageal reflux disease (GERD). Stimulated saliva contains greater concentration of bicarbonate ions and, thus, has increased buffering capacity.

The salivary $\mathrm{pH}$ of study groups $(1,2,3)$ were compared with respect to baseline and 2 minutes, 30 minutes, 1 hour and 2 hours post rinse and estimated by one way ANOVA. Estimation of $\mathrm{pH}$ of the salivary samples indicated that a single exposure to licorice aqueous as well as ethanolic extracts 
resulted in a rise in the $\mathrm{pH}$ of saliva, whereas chlorhexidine, which is established to have a neutral $\mathrm{pH}$, led to a very slight increase in $\mathrm{pH}$ of immediate (2 mins) post rinse salivary samples, which was statistically significant. Soldering et al. reported that in an in vivo acid production test, licoricecontaining gel was shown to inhibit acid production. ${ }^{18}$

The colony forming units (CFU) on blood agar (BA) from post rinse salivary samples collected at 2 minutes, 30 minutes, 1 hour and 2-hour intervals were compared among the three study groups with respect to baseline by one way ANOVA. The colony counts reduced from the baseline value in all the subsequent time intervals for the three groups. The number of colonies for alcoholic group was $1.19 \pm 1.42$ at 1 hour from baseline, was $0.03 \pm 0.03$ at 2 minutes from baseline for the Chlorhexidine group and for the aqueous group it was $3.38 \pm$ 1.15 at 30 minutes from baseline.

Streptococcus mutans is a contributor to an acidic response and to the initiation of dental caries and high counts of Streptococcus mutans is responsible for the low buffer capacity of saliva. ${ }^{19}$ Moreover, infection with mutans streptococci in young children is associated with inadequate toothbrushing. ${ }^{20}$ In the current study, the microbial count was significantly correlated with the frequency of tooth brushing for the ethanolic extract. This finding can be attributed to the increased production of saliva by the mechanical brushing action. In a study done by Kaneko $\mathrm{N}$ et al. fluorides in dentifrices had shown to affect the detectable levels of mutans streptococci. ${ }^{21}$

The antimicrobial activity of Licorice may be mostly due to phytochemicals like tannins, triterpenoid saponins and flavonoids. The presence of glycyrrhizin, an active principle is known to reduce bacterial growth and acid production. ${ }^{10}$ The present study shows licorice extracts can be used as preventive regimen for diseases of mouth cavity as it has both antimicrobial and cariostatic efficacy.

\section{CONCLUSIONS}

Present study revealed that ethanolic extract of licorice had better antimicrobial activity than aqueous extract. The efficacy of antimicrobial action of licorice at 30 minutes of rinsing and rise in salivary $\mathrm{pH}$ by use of both the preparations of licorice is significant as compared to the chlorhexidine group. Hence the antimicrobial and cariostatic efficacy of licorice extracts which was evident in the present study suggests and recommends that licorice can be used for prevention in clinical practice for diseases of mouth cavity especially dental caries.

Data sharing statement provided by the authors is available with the full text of this article at jemds.com.

Financial or other competing interests: None.

Disclosure forms provided by the authors are available with the full text of this article at jemds.com.

The authors would like to acknowledge all the study participants and the departments of Public Health Dentistry, Pharmacology and Microbiology.

\section{REFERENCES}

[1] Ismail AI, Ondersma S, Jedele JMW, et al. Evaluation of a brief tailored motivational intervention to prevent early childhood caries. Community Dent Oral Epidemiol 2011;39(5):433-48.

[2] Dhingra S, Marya CM, Jnaneswar A, et al. Role of sugar free chewing gums in oral health. J Oral Health Comm Dent 2015;9(1)35-9.

[3] Zickert I, Emilson CG, Krasse B. Effect of caries preventive measures in children highly infected with the bacterium Streptococcus mutans. Arch Oral Biol 1982;27(10):861-8.

[4] Russell R. Microbiological aspects of caries prevention. In: Murray J, Nunn JH, Steele JG, eds. Prevention of Oral Disease. $4^{\text {th }}$ edn. New York: Oxford University Press 2003:61-76.

[5] Jafer M, Patil S, Hosmani J, et al. Chemical plaque control strategies in the prevention of biofilm-associated oral diseases. J Contemp Dent Pract 2016;17(4):337-43.

[6] Pires JC, Junior CR, Pizzolitto AC. In vitro antimicrobial efficiency of a mouthwash containing triclosan/gantrez and sodium bicarbonate. Braz Oral Res 2007;21(4):3427.

[7] Sajjan P, Laxminarayan N, Kar PP, et al. Chlorhexidine as an antimicrobial agent in dentistry-a review. Oral Health Dent Manag 2016;15(2):93-100.

[8] Jone CG. Chlorhexidine is it still a gold standard? Periodontol 2000;15:55-62.

[9] Peters MC, Tallman JA, Braun TM, et al. Clinical reduction of S. mutansin pre-school children using a novel liquorice root extract lollipop: a pilot study. Eur Arch Paediatr Dent 2010;11(6):274-8

[10] Sidhu P, Shankargouda S, Rath A, et al. Therapeutic benefits of liquorice in dentistry. J Ayurveda Integr Med 2020;11(1):82-8.

[11] Mejàre I, Axelsson S, Dahlén G, et al. Caries risk assessment. A systematic review. Acta Odontol Scand 2014;72(2):81-91.

[12] CLSI. Performance standards for antimicrobial disk susceptibility test: approved standard. M02-A10, 10 edn. Vol. 29. Wayne, PA: Clinical and Laboratory Standards Institute 2009.

[13] Ahmad I, Mehmood Z, Mohammad F. Screening of some Indian medicinal plants for their antimicrobial properties. J Ethnopharmacol 1998;62(2):183-93.

[14] Segreto VA, Collins EM, Beiswanger BB, et al. A comparison of mouthrinses containing two concentrations of chlorhexidine. Journal of Periodontal Research 1986;21(Suppl 16):23-32.

[15] Inenaga K, Inangaki T, Hosokawa R, et al. Parotid salivary secretion induced by stimulation of periodontal regions with toothbrush in humans. J Med Invest 2009;56 Suppl:277.

[16] Hoek GH, Brand HS, Veerman ECI, et al. Toothbrushing affects the protein composition of whole saliva. Eur J Oral Sci 2002;110(6):480-1.

[17] Papas A, Singh M, Harrington D, et al. Stimulation of salivary flow with a powered toothbrush in a xerostomic population. Spec Care Dentist 2006;26(6):241-6. 
[18] Söderling E, Karjalainen S, Lille M, et al. The effect of liquorice extract-containing starch gel on the amount and microbial composition of plaque. Clin Oral Investig 2006;10(2):108-13.

[19] Kitasako Y, Ikeda M, Burrow MF, et al. Oral health status in relation to stimulated saliva buffering capacity among Japanese adults above or below 35 years of age. J Med Dent Sci 2006;53(4):175-80.
[20] Seow WK, Cheng E, Wan V. Effects of oral health education and tooth-brushing on mutans streptococci infection in young children. Pediatr Dent 2003;25(3):223-8.

[21] Kaneko N, Yoshihara A, Ida H, et al. Influence of a fluoride mouthrinse on mutans streptococci in schoolchildren. Caries Res 2006;40(6):501-7. 